\title{
HERANÇA DA RESISTÊNCIA À MANCHA-ANGULAR DO FEIJOEIRO E IDENTIFICAÇÃO DE MARCADORES MOLECULARES FLANQUEANDO O LOCO DE RESISTÊNCIA*
}

\author{
RONAN X. CORRÊA ${ }^{1,5}$, PEDRO I.V. GOOD-GOD ${ }^{1}$, MARIA L.P. OLIVEIRA', SILVIA NIETSCHE', \\ MAURILIOA. MOREIRA ${ }^{1,2,3} \&$ EVERALDO G. DE BARROS ${ }^{1,2,4}$
}

\begin{abstract}
${ }^{1}$ Universidade Federal de Viçosa, ${ }^{2}$ Instituto de Biotecnologia Aplicada à Agropecuária-BIOAGRO, ${ }^{3}$ Departamento de Bioquímica e Biologia Molecular e ${ }^{4}$ Departamento de Biologia Geral, 36571-000, Viçosa, MG, e-mail: ebarros@mail.ufv.br;

${ }^{5}$ Universidade Estadual de Santa Cruz, Departamento de Ciências Biológicas, 45650-000 Ilhéus, BA
\end{abstract}

(Aceito para publicação em 23/11/2000)

Autor para correspondência: Everaldo Gonçalves de Barros

CORRÊA, R.X., GOOD-GOD, P.I.V., OLIVEIRA, M.L.P., NIETSCHE, S., MOREIRA, M.A. \& BARROS, E.G. Herança da resistência à mancha-angular do feijoeiro e identificação de marcadores moleculares flanqueando o loco de resistência. Fitopatologia Brasileira 26:27-32. 2001.

\section{RESUMO}

A mancha-angular, cujo agente causal é o fungo Phaeoisariopsis griseola, é uma das principais doenças do feijoeiro comum (Phaseolus vulgaris). Os marcadores moleculares disponíveis ainda não são suficientes para monitorar todos os genes de resistência a essa doença. Por isso, objetivou-se neste trabalho estudar a herança da resistência aos patótipos 63.39 e 31.23 de $P$. griseola, em populações derivadas de 'Ouro Negro' (ON) e 'US Pinto 111' (PT), e identificar marcadores moleculares ligados a genes de resistência presentes nessas cultivares. Quando inoculadas com o patótipo 63.39 , as plantas ON, $\mathrm{F}_{1}(\mathrm{ON}$ x PT) e $3 / 4$ da população $F_{2}$ mostraram-se resistentes enquanto que $\mathrm{PT}$ e $1 / 4$ da população $F_{2}$ foram suscetíveis. Quando inoculadas com o patótipo 31.23 , as plantas PT e 1/4 das famílias $\mathrm{F}_{2: 3}$ foram resistentes e todas as demais, suscetíveis. Esses dados indicam que a resistência proveniente de ON é conferida por um gene dominante enquanto que a de PT, por um recessivo. Esses dois genes segregaram independentemente. Amostras de DNA das plantas $\mathrm{F}_{2}$ foram amplificadas pela técnica de RAPD (random amplified polymorphic DNA) de acordo com a estratégia de análise de bulks segregantes.

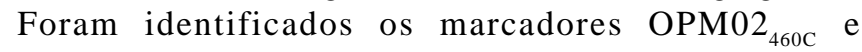
OPAA $19_{600 \mathrm{C}}$ respectivamente a 5,3 e 10 centimorgans (cM) do loco de resistência proveniente de ON. Eles flanqueiam este loco e, quando empregados simultaneamente, proporcionam uma eficiência de seleção de $97,4 \%$. Não foram identificados marcadores para o loco de resistência proveniente de PT.

Palavras-chave: Phaseolus vulgaris, Phaeoisariopsis griseola, eficiência de seleção por marcadores moleculares.

\section{ABSTRACT \\ Inheritance of resistance to the common bean angular leaf spot and identification of molecular markers flanking the resistance locus}

Angular leaf spot, caused by the fungus Phaeoisariopsis griseola, is one of the most important diseases affecting the common bean (Phaseolus vulgaris). Molecular markers linked to a few resistance genes have been identified, however, they are insufficient to monitor all the different sources of resistance. For this reason, in this work we aimed at studying the inheritance of resistance to $P$. griseola pathotypes 63.39 and 31.23 in populations derived from 'Ouro Negro' $(\mathrm{ON})$ and 'US Pinto 111' (PT), and identifying molecular markers linked to the resistance loci present in these two cultivars. The genitor ON, $\mathrm{F}_{1}(\mathrm{ON} \times \mathrm{PT})$ and $3 / 4$ of the $\mathrm{F}_{2}$ population were resistant to pathotype 63.39. The genitor PT and $1 / 4$ of

\footnotetext{
* Parte da Tese de Doutorado do primeiro autor apresentada à Universidade Federal de Viçosa em 1999. (Bolsista do CNPq).
}

$\mathrm{F}_{2}$ plants were susceptible. When pathotype 31.23 was used, the genitor PT and $1 / 4$ of $\mathrm{F}_{2: 3}$ families were resistant and all the other families were susceptible indicating that resistance of ON to pathotype 63.39 is conferred by a dominant gene while resistance of PT to pathotype 31.23 is conferred by a recessive gene. These two loci segregated independently. DNA samples extracted from $\mathrm{F}_{2}$ plants were amplified by the Random Amplified Polymorphic DNA (RAPD) technique and analyzed through the bulk segregant strategy. Two markers, OPM02 ${ }_{460 \mathrm{C}}$ and OPAA19 ${ }_{600 \mathrm{C}}$, located at 5.3 and 10 centimorgans $(\mathrm{cM})$ of the resistance locus, respectively, were identified in ON. These markers flank the resistance locus and their selection efficiency was $97.4 \%$ when used simultaneously. No markers were identified linked to the resistance locus present in PT. 


\section{INTRODUÇÃO}

A mancha-angular, cujo agente causal é o fungo Phaeoisariopsis griseola (Sacc.) Ferr., é de ocorrência generalizada nas regiões produtoras de feijão (Phaseolus vulgaris L.) do Brasil, podendo causar perdas que variam de 7 a $70 \%$ em lavouras de cultivares suscetíveis (Sartorato \& Rava, 1994). P. griseola apresenta grande variabilidade, tendo já sido identificados mais de 50 patótipos na América Latina (Pastor-Corrales \& Jara, 1995; Nietsche, 1997; Aparício, 1998). Devido ao grande número de patótipos, torna-se difícil encontrar cultivares de feijoeiro com ampla resistência à doença.

Estudos sobre a herança da resistência à manchaangular são essenciais em programas de melhoramento. A resistência a essa doença é atribuída a um, dois ou três genes, sendo alguns deles dominantes e, outros, recessivos (Barros et al., 1957; Cardona-Alvarez, 1962; Santos Filho et al., 1976; Singh \& Saini, 1980; Sartorato et al., 1993). Trabalhos mais recentes sobre a resistência presente nos genótipos AND 277, Mar-2, México 54 e Cornell 49-242, quando cruzados com a cultivar suscetível Rudá, revelaram herança monogênica dominante nos quatro cruzamentos (Carvalho et al., 1998; Ferreira et al., 1999a; Sartorato et al., 1999, Nietsche et al., 1999).

O uso de marcadores moleculares para genes de resistência a doenças, como auxiliar no processo de melhoramento, requer a identificação prévia desses marcadores em cultivares de interesse. Marcadores moleculares para alguns locos de resistência à mancha-angular já foram identificados. O marcador RAPD OPH13 ${ }_{490 \mathrm{C}}$ (Carvalho et al., 1998) está associado ao loco de resistência presente em 'AND-277' que confere resistência ao patótipo 63.23 de $P$. griseola. Os marcadores SCAR (sequence characterized amplified region) OPN02 ${ }_{890 \mathrm{C}}$ e RAPD OPAC14 $4_{2400 \mathrm{C}}$ (Sartorato et al., 1999) identificam os genes oriundos de 'México 54' que dão resistência ao patótipo 63.19 de P. griseola. O marcador OPE04 ${ }_{500 \mathrm{c}}$ (Ferreira et al., 1999b) está ligado ao loco de resistência da linhagem Mar-2, que confere resistência ao patótipo 63.39.

A cultivar Ouro Negro, amplamente plantada na Zona da Mata mineira devido a resistência a diversos patótipos da ferrugem apresenta, também, resistência à antracnose e à mancha-angular. Por isso, vem sendo recomendada para plantio comercial em vários estados brasileiros (Sartorato \& Rava, 1994; Faleiro et al., 1996). No entanto, a herança da resistência à mancha-angular presente nesta cultivar ainda não foi estudada, e marcadores moleculares para o(s) loco(s) de resistência à mancha-angular presente(s) em 'Ouro Negro' ainda não foram identificados. A disponibilidade de marcadores moleculares irá facilitar a piramidação desses genes, em geral provenientes de diferentes fontes de resistência, em cultivares superiores. Desta forma, objetivou-se estudar a herança da resistência à mancha-angular em populações derivadas do cruzamento de 'Ouro Negro' com 'US Pinto 111 ' e identificar marcadores moleculares para os genes presentes nestas cultivares.

\section{MATERIAL E MÉTODOS}

\section{Material genético e ensaios biológicos}

Em um primeiro ensaio, cinco plantas de cada uma das cultivares Ouro Negro (ON) e US Pinto 111 (PT) e 10 plantas dos híbridos recíprocos (ON/PT e PT/ON) foram testadas quanto a resistência aos patótipos 31.23, 31.55, 63.23, 63.31 e 63.39 de $P$. griseola. Estes patótipos correspondem a culturas monospóricas de isolados coletados em diferentes regiões produtoras de feijão do Estado de Minas Gerais. Os isolados foram caracterizados por Nietsche (1997) de acordo com a metodologia desenvolvida por Pastor-Corrales \& Jara (1995) e estão depositados na micoteca do Instituto de Biotecnologia Aplicada à Agropecuária (BIOAGRO) da Universidade Federal de Viçosa. Em um segundo ensaio, 302 plantas $\mathrm{F}_{2}$ derivadas do referido cruzamento foram inoculadas com o patótipo 63.39 de $P$. griseola. No terceiro ensaio, 101 famílias $\mathrm{F}_{2 \cdot 3}$, compostas de 12 plantas cada uma, derivadas da população $\mathrm{F}_{2}$ previamente analisada, foram inoculadas com o patótipo 31.23 de $P$. griseola.

As inoculações foram realizadas com auxílio de um pincel, empregando-se uma suspensão de $2 \times 10^{4}$ conídios/ $\mathrm{ml}$, contendo $0,03 \%$ de Tween 20. Após a inoculação, as plantas foram incubadas em câmara de nevoeiro ( $>90 \%$ de umidade relativa, a $21^{\circ} \mathrm{C}$ ) durante $48 \mathrm{~h}$ e transferidas para casa de vegetação onde a temperatura variou de 18 a $25^{\circ} \mathrm{C}$. As plantas foram pulverizadas com água, quatro vezes ao dia, durante cinco dias, utilizando um pulverizador manual. As avaliações foram realizadas 15 dias após a inoculação utilizando-se a escala proposta por Schoonhoven \& PastorCorrales (1987).

\section{Identificação de marcadores moleculares}

Amostras de DNA dos genitores e das plantas $\mathrm{F}_{2}$ foram extraídas de acordo com a metodologia de Doyle e Doyle (1990). Quantidades equivalentes de DNA de seis plantas $F_{2}$ resistentes constituíram o bulk representativo das plantas resistentes. Analogamente, DNA de seis plantas homozigotas suscetíveis formaram o bulk de plantas suscetíveis. Os bulks de DNA foram amplificados pela técnica de RAPD (Random Amplified Polymorphic DNA) (Williams et al., 1990), com 440 primers decâmeros (Operon Technologies, Alameda, CA, EUA).

A mistura de reação foi constituída de acordo com as concentrações empregadas por Corrêa et al. (1999) e as amplificações realizadas no termociclador modelo 9600 (Perkin Elmer-Cetus, Norwalk, CT, EUA), programado para quatro ciclos a $94{ }^{\circ} \mathrm{C}$ por $1 \mathrm{~min}, 35^{\circ} \mathrm{C}$ por 1 min e $72{ }^{\circ} \mathrm{C}$ por $2 \mathrm{~min} ; 40$ ciclos a $94^{\circ} \mathrm{C}$ por $15 \mathrm{~s}, 40^{\circ} \mathrm{C}$ por $30 \mathrm{se} 72{ }^{\circ} \mathrm{C}$ por $1 \mathrm{~min}$; e, um passo final a $72{ }^{\circ} \mathrm{C}$ por $7 \mathrm{~min}$. Os produtos das amplificações foram separados por eletroforese em gel de agarose 1,2\% imerso em TBE (Tris-borato $90 \mathrm{mM}$, EDTA 1 $\mathrm{mM}$ ), corados com brometo de etídio e fotografados sob luz ultravioleta.

Para efeito de normatização, os marcadores moleculares identificados neste trabalho ou nele citados apre- 
Herança da resistência à mancha-angular do feijoeiro e identificação...

sentam um número subscrito, que corresponde ao seu tamanho em pares de nucleotídeos (pb), e a letra $\mathrm{C}$, que indica que esses marcadores estão em fase de acoplamento com o gene de resistência.

\section{Análise de segregação e ligação genética}

A herança monogênica da resistência à manchaangular foi confirmada pelo teste qui-quadrado. Os primers que geraram bandas polimórficas foram usados para amplificar amostras de DNA dos 302 indivíduos $\mathrm{F}_{2}$. As análises de segregação foram realizadas utilizando-se o teste do qui-quadrado. As distâncias genéticas foram calculadas pela função de Kosambi, com o auxílio do programa Mapmaker EXP 3.0 (Lander et al., 1987; Lincoln et al., 1992). Os desvios-padrão das distâncias genéticas foram calculados de acordo com a expressão desenvolvida por Hanafey et al. (1992), apropriada para dados do tipo $\mathrm{F}_{2}$ em acoplamento puro, como se segue:

$$
D=\left(1,40+0,170 \theta-0,00262 \theta^{2}\right) \sqrt{\frac{100}{N}}
$$

em que $\mathrm{D}=$ desvio-padrão em porcentagem de recombinação, $\theta=$ porcentagem de recombinação e $\mathrm{N}=$ tamanho da população.

\section{RESULTADOS E DISCUSSÃO}

\section{Herança da resistência}

As cultivares ON e PT foram suscetíveis aos patótipos 31.55, 63.23 e 63.31 de P. griseola. Segundo Nietsche (1997), estes três patótipos bem como o 63.39 mostraram-se bastante virulentos quando testados em diferentes fontes de resistência à mancha-angular. A cultivar $\mathrm{ON}$ e a população $\mathrm{F}_{1}(\mathrm{ON}$ x PT) foram resistentes ao patótipo 63.39 e suscetíveis ao patótipo 31.23. Por outro lado, a cultivar PT foi suscetível ao 63.39 e resistente ao 31.23 (Tabela 1). Estes dados evidenciam que o gene de resistência de ON foi efetivo tanto em homozigose quanto em heterozigose, ao passo que o gene de resistência de PT não conferiu resistência quando se encontrava em heterozigose.

A observação da proporção de três plantas resistentes para uma suscetível, na população $F_{2}$ derivada de $\mathrm{ON}$ inoculada com o patótipo 63.39 (Tabela 2), confirmou a herança monogênica dominante do gene proveniente desta cultivar. Por outro lado, a segregação de uma planta resistente para três suscetíveis na população básica, quando as plantas foram inoculadas com o patótipo 31.23 (Tabela 2), confirmou que o gene de PT apresenta herança monogênica recessiva. Estes resultados estão de acordo com os estudos prévios sobre a herança da resistência à mancha-angular, que têm revelado a existência de alguns genes dominantes e outros recessivos, provenientes de diferentes fontes de resistência (Barros et al., 1957; Cardona-Alvarez, 1962; Santos Filho et al., 1976; Singh \& Saini, 1980; Sartorato et al., 1993; Nietsche, 1997; Carvalho et al., 1998; Ferreira, 1999a).
TABELA 1 - Caracterização fenotípica dos genitores Ouro Negro e US Pinto 111 e da geração $F_{1}$ de Phaseolus vulgaris quanto às respectivas reações a diferentes patótipos de Phaeoisariopsis griseola

\begin{tabular}{cccccc}
\hline \hline \multirow{2}{*}{ Patótipo } & \multicolumn{3}{c}{ Fenótipo dos genitores e $\mathbf{F}_{\mathbf{1}}$} & \multirow{2}{*}{$\begin{array}{c}\text { Fonte de } \\
\text { resistência }\end{array}$} \\
\cline { 2 - 5 } & $\mathbf{O N}^{\mathbf{a}}$ & $\mathbf{F}_{\mathbf{1}(\mathbf{P T} / \mathbf{O N})}$ & $\mathbf{F}_{\mathbf{1}(\mathbf{O N} / \mathrm{PT})}$ & $\mathbf{P T}^{\mathbf{b}}$ & \\
\hline 63.39 & $\mathrm{R}^{\mathrm{c}}$ & $\mathrm{R}$ & $\mathrm{R}$ & $\mathrm{S}^{\mathrm{d}}$ & $\mathrm{ON}$ \\
31.23 & $\mathrm{~S}$ & $\mathrm{~S}$ & $\mathrm{~S}$ & $\mathrm{R}$ & $\mathrm{PT}$ \\
31.55 & $\mathrm{~S}$ & $\mathrm{~S}$ & $\mathrm{~S}$ & $\mathrm{~S}$ & - \\
63.23 & $\mathrm{~S}$ & $\mathrm{~S}$ & $\mathrm{~S}$ & $\mathrm{~S}$ & - \\
63.31 & $\mathrm{~S}$ & $\mathrm{~S}$ & $\mathrm{~S}$ & $\mathrm{~S}$ & - \\
\hline
\end{tabular}

"ON = 'Ouro Negro'

${ }^{\mathrm{b}} \mathrm{PT}=$ 'US Pinto 111'

${ }^{\mathrm{c}} \mathrm{R}=$ planta resistente

${ }^{\mathrm{d}} \mathrm{S}=$ planta suscetível

Os cruzamentos foram confirmados pela presença de características típicas do genitor masculino no híbrido: $\mathrm{F}_{1(\mathrm{PT} / \mathrm{ON})}$, cor de flor; $\mathrm{e}_{1(\mathrm{ON} / \mathrm{PT}) \text {, }}$ bandas RAPD.

TABELA 2 - Segregação dos genes de resistência à mancha-angular provenientes entre os cultivares de feijoeiro comum (Phaseolus vulgaris) Ouro Negro e US Pinto 111 inoculados com dois patótipos de Phaeoisariopsis griseola

\begin{tabular}{cccccc}
\hline \multirow{2}{*}{ Patótipo } & \multirow{2}{*}{ Geração } & \multicolumn{2}{c}{ No de plantas R:S $^{\mathbf{2}} \boldsymbol{\chi}^{\mathbf{2}}$} & \multirow{2}{*}{ Prob. } \\
\cline { 3 - 4 } & & $\mathbf{E}^{\mathbf{a}}$ & $\mathbf{O}$ & & \\
\hline (A) 63.39 & $\mathrm{~F}_{2}$ & $3: 1$ & $231: 71$ & 0,36 & $0,54^{\text {ns1 }}$ \\
(B) 31.23 & $\mathrm{~F}_{2: 3}$ & $1: 3$ & $31: 70$ & 2,10 & $0,15^{\mathrm{ns} 1}$ \\
(A/B) & $\mathrm{F}_{2}$ & $9: 3: 3: 1$ & $60: 17: 12: 11$ & 6,45 & $0,11^{\mathrm{ns} 2}$ \\
\hline
\end{tabular}

aRazão esperada em $\mathrm{F}_{2}: 3: 1$ = herança monogênica dominante, 1:3= herança monogênica recessiva e 9:3:3:1 = segregação de dois genes independentes

${ }^{\text {nsl }}$ Não significativo e as frequiências observadas $(\mathrm{O})$ de plantas R para $\mathrm{S}$ não diferem estatisticamente da razão esperada (E) para herança monogênica pelo teste qui-quadrado a $5 \%$ de probabilidade.

${ }^{\text {ns2 } N a ̃ o ~ s i g n i f i c a t i v o ~ e ~ a ~ f r e q u i e ̂ n c i a ~ o b s e r v a d a ~}(\mathrm{O})$ não difere estatisticamente da razão esperada (E) para segregação de dois genes independentes pelo teste qui-quadrado a $5 \%$ de probabilidade.

Os dois locos de resistência à mancha-angular (para os patótipos 63.39 e 31.23) segregaram de forma independente (Tabela 2). A identificação de dois locos de resistência irá permitir o estabelecimento de cultivares com resistência mais duradoura do que ON e PT separadamente porque o patógeno terá que apresentar dois genes de virulência para "quebrar" os genes de resistência identificados. A estratégia de introdução de vários genes de resistência em cultivares superiores é a mais apropriada para agrupar resistências conferidas por "genes maiores" (Borém, 1998).

$\mathrm{O}$ estudo da herança da resistência à mancha-angular 
na população derivada de PT/ON revelou que estas duas cultivares possuem diferentes genes de resistência à manchaangular. Estudos de alelismos poderão ser realizados no futuro visando descrever a identidade desses genes. Embora existam outras fontes já descritas para conferir resistência aos patótipos utilizados neste trabalho (Nietsche et al., 1999), ON e PT se apresentam como fontes alternativas às que vem sendo descritas na literatura. Além disso, nos programas de melhoramento do feijoeiro comum que já empregam estas cultivares como fontes de outros genes de interesse, não seria necessário utilizar outras fontes para introduzir resistência aos patótipos 63.39 e 31.23 de $P$. griseola.

\section{Identificação de marcadores RAPD}

Foram utilizados 440 primers decâmeros para amplificar os bulks de DNA de plantas $\mathrm{F}_{2}$ contrastantes para resistência à mancha-angular proveniente de $\mathrm{ON}$. Destes, dois evidenciaram polimorfismos. A banda polimórfica de 460 pares de bases (pb), gerada pelo primer OPM02 (Figura 1), co-segregou com o loco de resistência ao patótipo 63.39 de $P$.

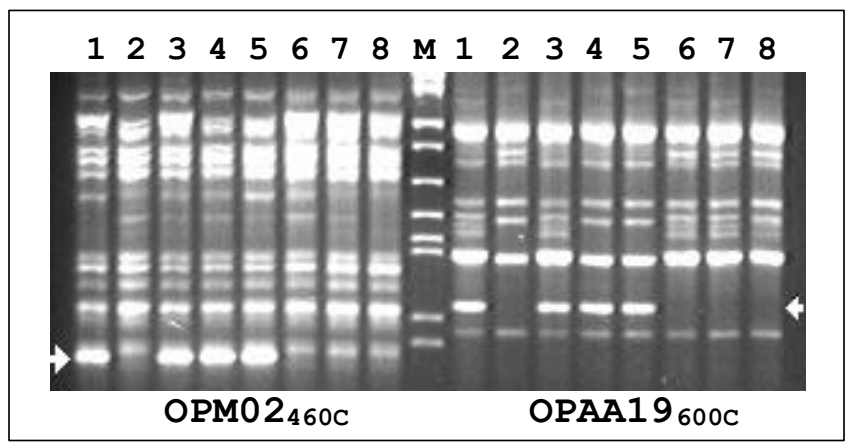

FIG. 1 - Análise eletroforética dos produtos de amplificação do DNA com os primers OPM02 e OPAA19. As setas indicam os marcadores

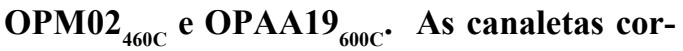
respondem a: (1) ON, (2) PT, (3 a 5) plantas $F_{2}$ resistentes e (6 a 8) plantas $\mathrm{F}_{2}$ suscetíveis. $M$ refere-se a DNA do fago lambda digerido com as enzimas EcoRI, HindIII e BamHI (marcadores de tamanho). griseola quando testada em 302 plantas $\mathrm{F}_{2}$ originadas do cruzamento entre PT e ON (Tabela 3). Nesta mesma população, a banda polimórfica de $600 \mathrm{pb}$, gerada pelo primer OPAA19, também co-segregou com o loco de resistência de ON à mancha-angular (Tabela 3). Estes dois marcadores mostraramse ligados em acoplamento a 5,3 e $10 \mathrm{cM}$, respectivamente, do loco de resistência. O mapeamento desses dois marcadores demonstrou que, na realidade, eles estão flanqueando este loco (Figura 2).

A eficiência de seleção (ES) baseada nos marcadores moleculares ligados ao loco de ON foi calculada pela razão entre o número de acertos na seleção com base no marcador pelo total de plantas analisadas. Quando foi considerado apenas um marcador de cada vez, a ES de OPAA $19_{600 \mathrm{C}}$ foi de $90,1 \%$ e a de OPM02 $2_{460 \mathrm{C}}$ foi de $94,7 \%$. No entanto, quando os dois marcadores foram utilizados simultaneamente, a ES foi de 97,4\%. Segundo Griffths et al. (1998), considerando-se que a frequiência de recombinação entre um loco com aqueles que o flanqueiam são independentes, então a freqüência dos recombinantes duplos será o produto das distâncias entre o loco considerado e os locos que o flanqueiam. Portanto, a maior eficiência observada neste trabalho, quando foram utilizados os dois marcadores simultaneamente, pode ser

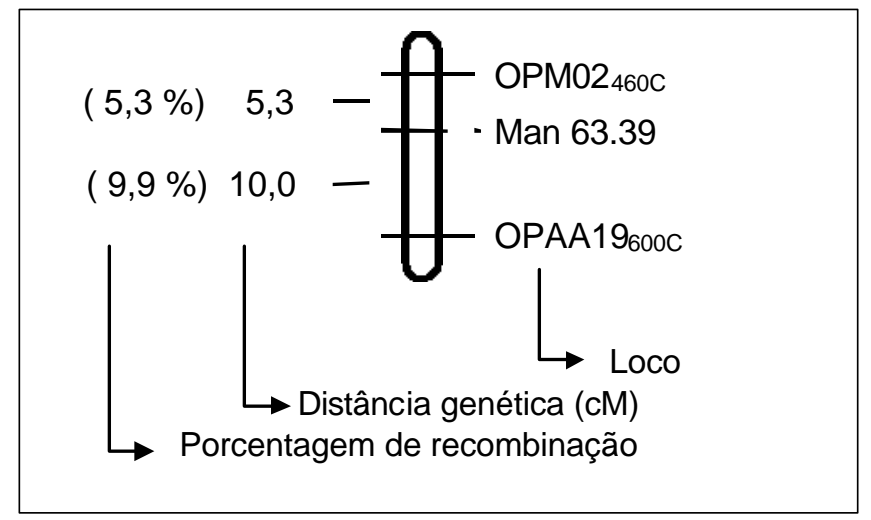

FIG. 2 - Posições relativas e distâncias genéticas entre o loco de resistência ao patótipo 63.39 de Phaeoisariopsis griseola (Man 63.39) e os marcadores RAPD OPM02 ${ }_{460 \mathrm{C}}$ e OPAA19 ${ }_{600}{ }^{\circ}$

TABELA 3 - Herança dos marcadores moleculares e testes de suas ligações genéticas ao gene de resistência à mancha-angular $(P h)$ na população $\mathrm{F}_{2(\mathrm{PT} / \mathrm{ON})}$ de Phaseolus vulgaris inoculada com o patótipo 63.39 de Phaeoisariopsis griseola

\begin{tabular}{|c|c|c|c|c|c|}
\hline Loco & Razão esperada & $\begin{array}{c}\text { Freqüência } \\
\text { observada }\end{array}$ & Qui-quadrado & Probabilidade & $\begin{array}{c}\text { Distância (cM) e } \\
\text { desvio padrão }\end{array}$ \\
\hline $\mathrm{OPM} 02_{460 \mathrm{C}}$ & $3: 1$ & $240: 62$ & 3,22 & 0,08 & - \\
\hline OPAA $19_{600 \mathrm{C}}$ & $3: 1$ & $232: 70$ & 0,53 & 0,47 & - \\
\hline $\mathrm{Ph} / \mathrm{OPM} 02_{460 \mathrm{C}}$ & $9: 3: 3: 1$ & $229: 11: 3: 59$ & 193,3 & $<0,0001$ & $5,3 \pm 1,30$ \\
\hline$P h /$ OPAA $19_{600 \mathrm{C}}$ & $9: 3: 3: 1$ & 220:11:12:59 & 172,02 & $<0,0001$ & $10,0 \pm 1,62$ \\
\hline
\end{tabular}

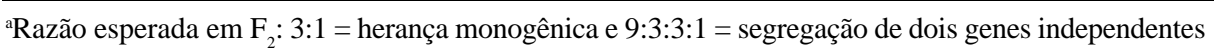


Herança da resistência à mancha-angular do feijoeiro e identificação...

explicada pela expectativa de menor freqüência de recombinantes duplos que constituiriam os indivíduos selecionados ou descartados erroneamente.

Além de desenvolver estes marcadores para o loco de resistência proveniente de ON, também foram testados marcadores moleculares previamente identificados em outras fontes de resistência. Os marcadores OPH13 ${ }_{490 \mathrm{C}}$ (Carvalho et al., 1998), OPE04 ${ }_{500 \mathrm{C}}$ (Ferreira, 1999b), OPN02 ${ }_{890 \mathrm{C}} \mathrm{e}$ OPAC14 $_{2400 \mathrm{C}}$ (Sartorato et al. 1999), identificados a partir de cruzamentos distintos em que as plantas foram inoculadas com patótipos de $P$. griseola diferentes dos que foram empregados neste trabalho, não apresentaram ligação à resistência presente nas populações derivadas de ON/PT (dados não mostrados). Esses fatos indicam que os genes de $\mathrm{ON}$ e de PT devem ser diferentes daqueles relatados para as outras fontes de resistência. Portanto, os marcadores OPAA $19_{600 \mathrm{C}}$ e OPM02 ${ }_{460 \mathrm{C}}$, identificados neste trabalho, serão úteis para monitorar o gene proveniente de $\mathrm{ON}$ em programas que utilizam essa cultivar, a qual é amplamente plantada no Brasil. Além disso, poderão ser empregados para amplificar DNA de diferentes fontes de resistência à mancha-angular, visando descrever a identidade do gene proveniente de ON.

\section{AGRADECIMENTOS}

Os autores são gratos aos pesquisadores A.L. AlzateMarin, A. Sartorato e I. Shuster pelas sugestões apresentadas e à FAPEMIG pelo auxílio financeiro.

\section{REFERÊNCIAS BIBLIOGRÁFICAS}

APARÍCIO, B.H.E. Caracterización de la diversidad molecular y la virulencia de aislamentos del hongo Phaeoisariopsis griseola de Brasil y Bolivia (Trabajo de Grado). Cali (Colombia): Universidad del Valle. 1998.

BARROS, O., CARDONA, C., CARDEÑOSA, R. \& SKILES, R.L. Angular leaf spot o bean in Colombia. Plant Disease Report 42:420-424. 1958.

BORÉM, A. Melhoramento de plantas. 2 ed. Viçosa: Editora UFV. 1998.

CARDONA-ALVAREZ, C. Herencia de la resistencia a la mancha angular en frijol. Agronomía Tropical 18:330331.1962

CARVALHO, G.A., PAULA-JUNIOR, T.J., ALZATEMARIN, A.L., NIETSCHE, S., BARROS, E.G. \& MOREIRA, M.A. Herança da resistência da linhagem AND 277 de feijoeiro comum à raça 63.23 de Phaeoisariopsis griseola e identificação de marcador RAPD ligado ao gene de resistência. Fitopatologia Brasileira 23:482-485. 1998.

CORREAA, R.X., ABDELNOOR, R.V., FALEIRO, F.G., CRUZ, C.D., MOREIRA, M.A. \& BARROS, E.G. Genetic distances in soybean based on RAPD markers. Bragantia 58:15-22. 1999.

DOYLE, J.J. \& DOYLE, J.L. Isolation of plant DNA from fresh tissue. Focus 12:13-15. 1990

FALEIRO, F.G., PAULA JUNIOR, T.J., BARROS, E.G. \& MOREIRA, M.A. Resistência de cultivares de feijoeiro comum a Uromyces appendiculatus da Zona da Mata de Minas Gerais. Fitopatologia Brasileira 21:123-125. 1996.

FERREIRA, C.F., BORÉM, A., CARVALHO, G.A., NIETSCHE, S., PAULA JR, T.J., BARROS, E.G. \& MOREIRA, M. A. Herança da resistência do feijoeiro a mancha angular. Fitopatologia Brasileira 24: 391-393. 1999a.

FERREIRA, C.F., BORÉM, A., CARVALHO, G.A., NIETSCHE, S., PAULA JR, T.J., BARROS, E.G. \& MOREIRA, M.A. Identificação de marcador RAPD ligado ao gene de resistência à raça 63.39 da manchaangular do feijoeiro. Bragantia 58:247-252. 1999 b.

GRIFFTHS, A.J.F., MILLER, J.H., SUZUKI, D.T., LEWONTIN, R.C. \& GELBART, W.M. Introdução à Genética. Trad. Paulo Armando Motta. 6a ed. Rio de Janeiro: Guanabara Koogan. 1998.

HANAFEY, M.K., RAFALSKI, J.A., TINGEY, S.V. \& WILLIAMS, J.G.K. Mapping efficiency dominant and codominant markers in F2, backcross, and recombinant inbred populations. In: MAIZE GENETICS CONFERENCE, Minneapolis. Proceedings... Madison, WI: ASA,1992. p. 18-30 (Joint Plant Breeding Symposia Series).

LANDER, E., GREEN, P., ABRAHAMSON, J., BARLON, A., DALEY, M., LINCOLN, S. \& NEWBURG, L. MAPMAKER: an interactive computer package for constructing primary genetic linkages maps of experimental and natural populations. Genomics 1:174181.1987.

LINCOLN, S., DALY, M. \& LANDER, E. Constructing genetic maps with MAPMAKER/EXP 3.0. 3.ed. [S.L.]: Whitehead Institute, Technical Report. 1992. 86p.

NIETSCHE, S. Identificação de raças de Phaeoisariopsis griseola e determinação de fontes de resistência em Phaseolus vulgaris. (Dissertação de Mestrado). Viçosa. Universidade Federal de Viçosa, 1997.

NIETSCHE, S., BORÉM, A., CAIXETA, E.T., BARROS, E.V. \& MOREIRA, M.A. Marcadores RAPD e SCAR ligados ao gene de resistência à mancha-angular do feijoeiro. Genetics and Molecular Biology 22:660. 1999. (Supplement)

PASTOR-CORRALES, M.A. \& JARA, C.E. La evolución de Phaeoisariopis griseola com el frijol comum en America Latina. Fitopalogía Colombiana 19:15-24. 1995.

SANTOS FILHO, H.P., FERRAZ, S. \& VIEIRA, C. Resistência à mancha angular (Isariopsis griseola Sacc.) no feijoeiro (Phaseolus vulgaris L.). Revista Ceres 23:226-230. 1976.

SARTORATO, A. \& RAVA, C.A. Mancha-angular. In: SARTORATO, A. \& RAVA, C.A. (Eds.). Principais doenças do feijoeiro comum e seu controle. Brasília: 
EMBRAPA, 1994. pp. 41-68.

SARTORATO, A., ZIMMERMANN, M.J.O., RAVA, C.A. \& CARNEIRO, J.E.S. Inheritance of dry bean resistance to Isariopsis griseola. Summa Phytopathologica 19:30. 1993.

SARTORATO, A., NIETSCHE, S., BARROS, E.G. \& MOREIRA, M.A. SCAR markers linked to angular leaf spot resistance gene in common bean. Annual Report Bean Improvement Cooperative 42:21-22. 1999.

SCHOONHOVEN, A. \& PASTOR-CORRALES, M.A.
Standard system for evaluation of bean germplasm. Cali, Colombia: CIAT. 1987.

SINGH, A.K. \& SAINI, S.S. Inheritance of resistance to angular leaf spot (Isariopsis griseola Sacc.) in french bean (Phaseolus vulgaris L.). Euphytica 29:175-176. 1980.

WILLIAMS, J.G.K., KUBELIK, A.R., LIVAK, K.J., RAFALSKI, J.A.,TINGEY \& S.V. DNA polymorphisms amplified by arbitrary primers are useful as genetic markers. Nucleic Acids Research 18:6531-6535. 1990. 